\title{
ASSESSMENT OF RANS AND DES METHODS FOR THE AHMED BODY
}

\author{
E. Guilmineau, G.B. Deng, A. Leroyer, P. Queutey, M. Visonneau and J. Wackers \\ LHEEA, CNRS UMR 6598, Ecole Centrale de Nantes \\ 1 rue de la No, BP 92101, 44321 Nantes Cedex 3, France \\ e-mail: Emmanuel.Guilmineau@ec-nantes.fr
}

Keywords: DES models, IDDES, RANS, Ahmed body, Turbulence models.

\begin{abstract}
This paper presents numerical simulations for the prediction of the flow around the Ahmed body, with the $25^{\circ}$ and $35^{\circ}$ slant angles, obtained with the flow solver ISIS-CFD. A RANS (Reynolds Averaged Navier-Stokes) turbulence model, as EARSM (Explicit Algebraic Stress Model) and two hybrid RANS-LES models, as DES (Detached Eddy Simulation) and IDDES (Improved Delay Detached Eddy Simulation) models, are used. All these turbulence models are based on the $k-\omega$ model.The flow for the slant angle $35^{\circ}$ is well predicted by all turbulence models with a slight advantage for the IDDES model. However, for the flow with the slant angle $25^{\circ}$, only the IDDES hybrid RANS-LES model predict the recirculation bubble on the slant.
\end{abstract}




\section{INTRODUCTION}

The external aerodynamics of a car determines many relevant aspects of an automobile such as stability, comfort and fuel consumption at high cruising speed [1]. The flow around vehicles is characterized by highly turbulent and three-dimensional separations. There is a growing need for more insight into the physical features of these dynamical flows, on one hand, and powerful numerical tools to analyze them on the other hand. Computations based on ReynoldsAveraged Navier-Stokes (RANS) equations are common in industry today. Although they are very successful in predicting many parts of the flow around a vehicle, they are unable to predict unsteadiness in the wake regions. The failure in predicting the base pressure is the major reason for large discrepancy in drag prediction between experiments and numerical simulations.

In an attempt to improve the predictive capabilities of turbulence models in highly separated regions, Spalart et al. [2] proposed a hybrid approach which combines features of classical RANS formulations with elements of Large Eddy Simulations (LES) method. This concept has been termed Detached Eddy Simulation (DES) and is based on the idea of covering the boundary layer by a RANS model and of switching the model to a LES mode in detached regions. Compared to classical LES methods, DES save orders of magnitude of computing power for high Reynolds number flows, due to the moderated costs of a RANS model in the boundary layer region, but still offers some of the advantage of a LES method in separated regions. A variant of the DES model, like Improved Delayed DES, IDDES, seems to be attractive [3].

The purpose of this paper is to conduct a validation of the flow around the Ahmed body [4] to compare RANS model and hybrid RANS-LES methodologies. The Ahmed body is a generic car geometry comprising a flat front with rounded corners and a sharp slanted rear surface. A detailed experimental study by Lienhart and Becker [5] has been performed. This was undertaken for the $25^{\circ}$ and $35^{\circ}$ slant angles. While representing a much simplified car, the Ahmed body provides many of the flow features of a realistic car, such as the large 3D separation region behind the car body and the roll up of the vortices at the rear corners. The wake behind the body is a complex interaction between the counter-rotating vortices and the highly turbulent recirculating flow. The structure of the wake and the reattachment point of the recirculation bubble depend on the angle of the rear slant. At $35^{\circ}$, the counter-rotating vortices are weaker, which results in the flow being completely separated over the entire slant. As the angle is reduced, the strength of the counter-rotating vortices is increased relative to the recirculating turbulent flow. At $25^{\circ}$, the flow is able to reattach over the slant.

Both $25^{\circ}$ and $35^{\circ}$ slant back angles are investigated in this study to assess the capability of each turbulence model to capture the important changes in flow physics. These turbulence models are used with the ISIS-CFD unstructured finite-volume solver.

\section{TEST CASE}

The Ahmed model used for the numerical simulations is shown in Figure 1 1 . The slant angle is adjustable and is the main variable model-parameter in the experimental investigations [4]. In this paper, the $25^{\circ}$ and $35^{\circ}$ slant angles are investigated. The length of the model is $\mathrm{L}=1044$ $\mathrm{mm}$, the width is $\mathrm{W}=369 \mathrm{~mm}$, the height is $\mathrm{H}=288 \mathrm{~mm}$. The length of the slant is $1=222$ $\mathrm{mm}$. The ground clearance is $\mathrm{G}=50 \mathrm{~mm}$, and the diameter of the four feet, which are used to secure the model to the floor of the wind tunnel, is $\phi=30 \mathrm{~mm}$. The reference axis $(\mathrm{X}, \mathrm{Y}, \mathrm{Z})$ is linked to the model. The origin of these axes is related to the point $\mathrm{O}$ located on the floor of the wind tunnel at the base of the model ans in the symmetry plane of the model, see Figure 1 .

The upstream velocity is $U_{\infty}=40 \mathrm{~m} / \mathrm{s}$. The Reynolds number, based on the length of the 


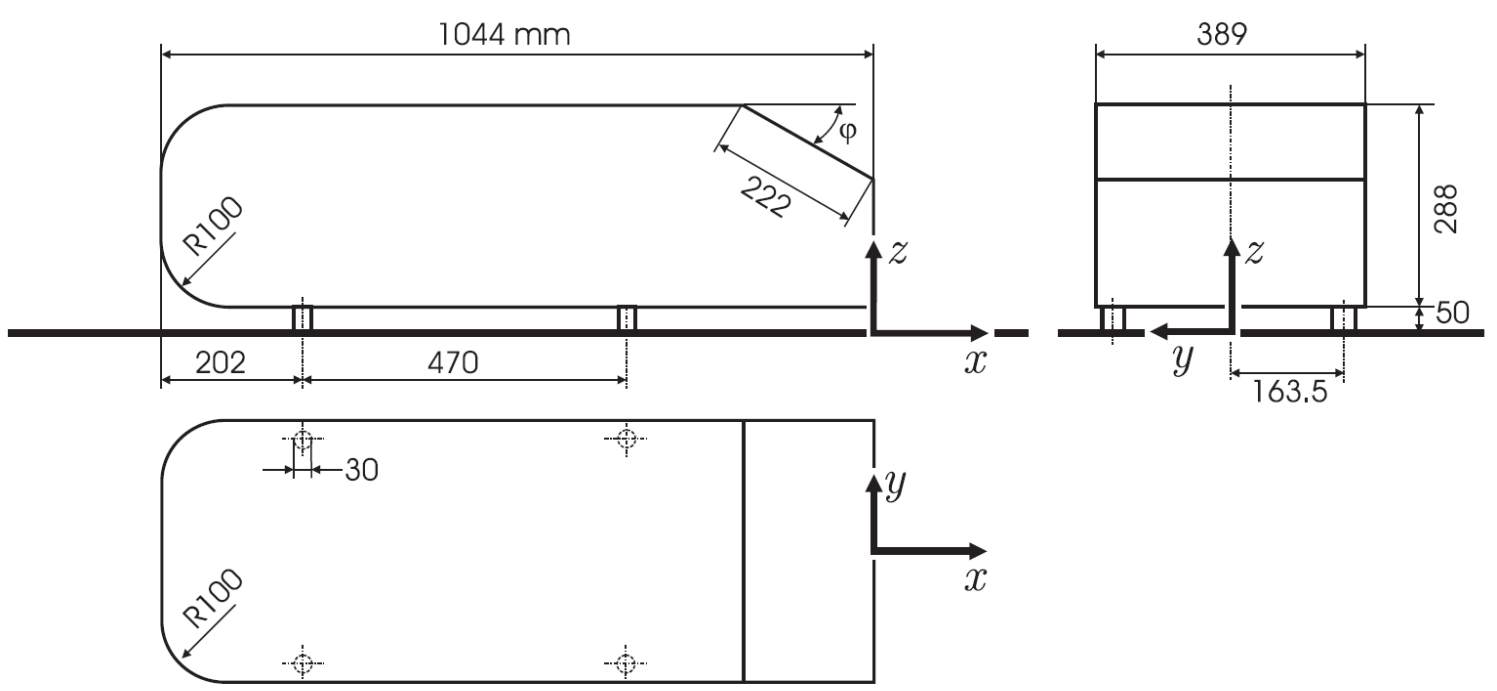

Figure 1: Ahmed body model with the coordinates system used. Distances are in $\mathrm{mm}$.

model, is $\operatorname{Re}=2.78 \times 10^{6}$. Measurements were performed by Lienhart and Becker [5].

\section{FLOW SOLVER}

ISIS-CFD, developed by the Ecole Centrale de Nantes and CNRS and available as a part of the FINE/Marine computing suite, is an incompressible unsteady Reynolds-averaged NavierStokes (URANS) method. The solver is based on the finite volume method to build the spatial discretization of the transport equations. The unstructured discretization is face-based, which means that cells with an arbitrary number of arbitrarily shaped faces are accepted. A second order backward difference scheme is used to discretize time. The solver can simulate both steady and unsteady flows. The velocity field is obtained from the momentum conservation equations and the pressure field is extracted from the mass equation constraint, or continuity equation, transformed into a pressure equation. In the case of turbulent flows, transport equations for the variables in the turbulence model are added to the discretization. A detailed description of the solver is given by Queutey and Visonneau [6].

The solver features sophisticated turbulence models: apart from the classical two-equation k- $\varepsilon$ and k- $\omega$ models, the anisotropic two-equation Explicit Algebraic Reynolds Stress Model (EARSM), as well as Reynolds Stress Transport Models, are available, see Duvigneau et al. [7] and Deng and Visonneau [8]. All these are RANS models. A Detached Eddy Simulation (DES) approach has been introduced, see Guilmineau et al. [9]. Recently, some modifications of this formulation proposed by Griskevich et al. [10] includes recalibrated empirical constants in the shielding function and a simplification of the original Spalart-Allmaras-based formulation. This new model is called Improved Delayed Detached Eddy Simulation (IDDES).

\section{NUMERICAL SIMULATION SET-UP}

The computational domain starts $2 \mathrm{~L}$ in front of the model and extends to $5 \mathrm{~L}$ behind the model. The width of the domain is $1.87 \mathrm{~m}$ and its height is $1.4 \mathrm{~m}$. These dimensions are recommended for the ERCOFTAC workshop on Refined Turbulence Modelling [11]. The mesh is generated using Hexpress, an automatic unstructured mesh generator. This software generates 
meshes containing only hexahedrals. For the surface of the car model and the floor, a no-slip boundary condition is used and the wall normal resolution is set $0.0007 \mathrm{~mm}$, i.e; $\mathrm{y}^{+} \leq 0.7$. For the $25^{\circ}$ slant angle, the mesh consists of $23.1 \times 10^{6}$ cells and the model is described by 384,090 faces. For the $35^{\circ}$ slant angle, the mesh consists of $22.2 \times 10^{6}$ cells and the model is described by 379,358 faces.

To capture the unsteadiness of the flow, an unsteady simulation is carried out with the RANS turbulence models. In this case the time step is $\Delta \mathrm{t}=0.001 \mathrm{~s}$. The numerical simulation converge to a steady flow. With the hybrid RANS-LES models, the flow is by nature unsteady and the time step is $\Delta \mathrm{t}=2.5 \times 10^{-4} \mathrm{~s}$. The averaging time, $\mathrm{t} \times U_{\infty} / \mathrm{L}$, in the simulations is 40 .

\section{RESULTS}

\section{$5.135^{\circ}$ slant angle}

Figure 2 shows the vortex structures by means of the dimensionless Q-criterion for the Ahmed body with the $35^{\circ}$ slant angle. For the hybrid RANS-LES models, the visualizations presents the mean flow. The vortex are more pronounced with the hybrid RANS-LES approaches than the RANS model.

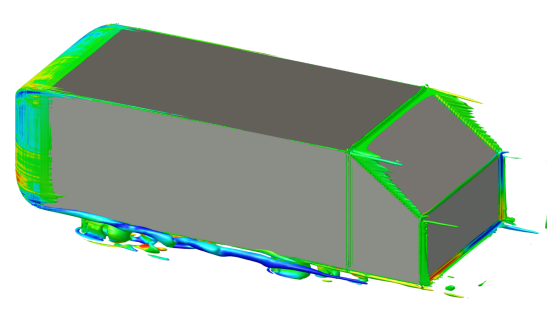

(a) EARSM

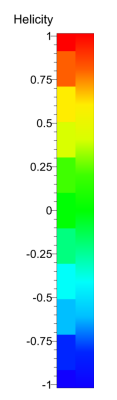

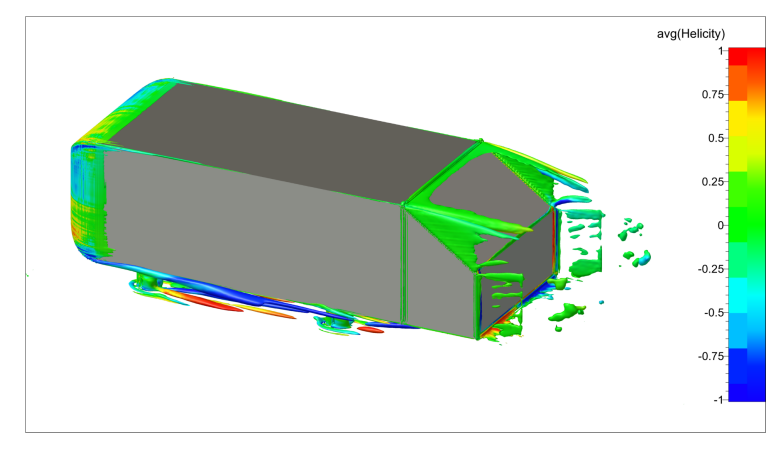

(b) DES (avg flow)

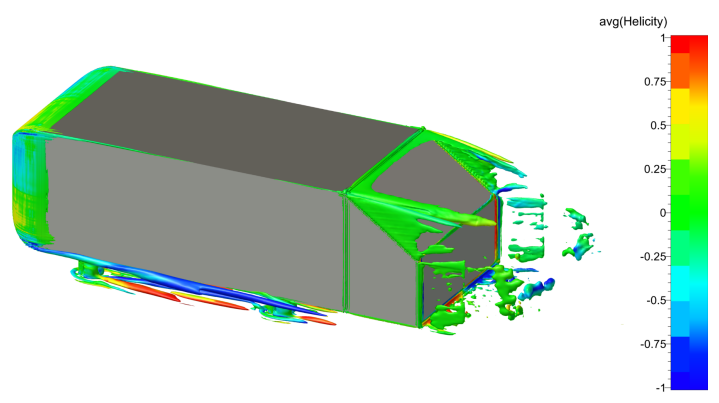

(c) IDDES (avg flow)

Figure 2: $35^{\circ}$ slant angle - Vortex structures around the Ahmed body visualized by iso-surfaces of the nondimensional Q-criterion $(\mathrm{Q}=50)$.

The flow in the symmetry plane obtained with all turbulence models is reported in Figure 3 together with the experimental results [5]. With the EARSM model, a massive separation in the wake is predicted while with the hybrid RANS-LES approaches, this recirculation is smaller and in better agreement with the measurements. With this turbulence modelization, a small separation is observed at the end of the slant. In the experiments, it is difficult to say if this 
recirculation is present. The shape of the lowest recirculation in the wake obtained with the IDDES model is in better agreement with the experiments than this obtained with the DES approach.

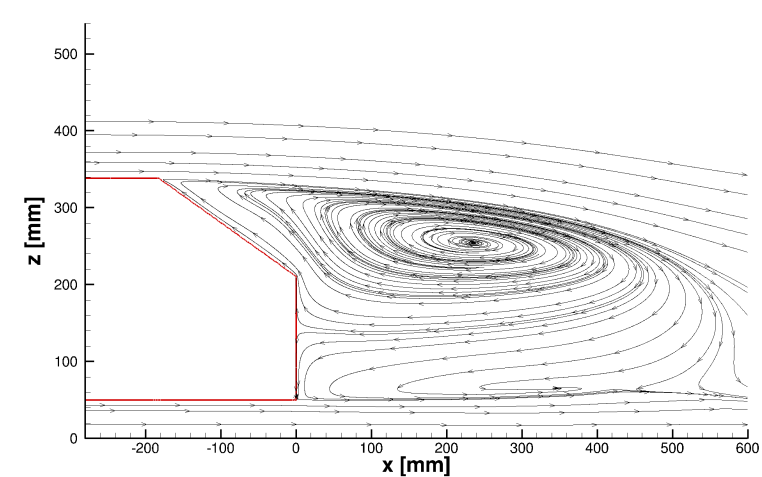

(a) EARSM

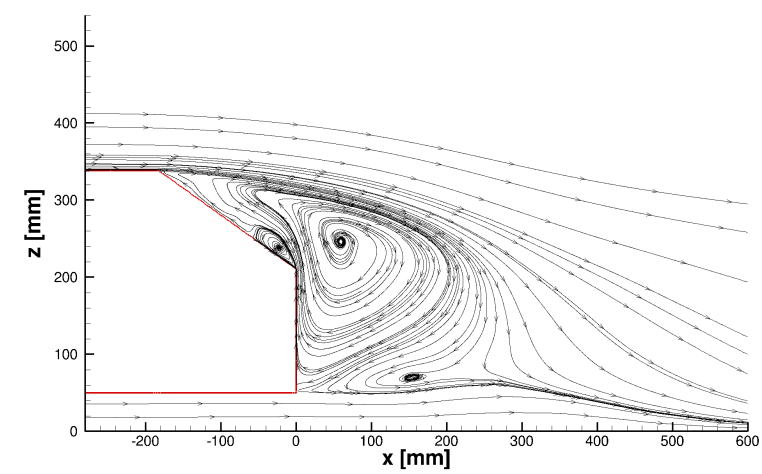

(c) IDDES (avg)

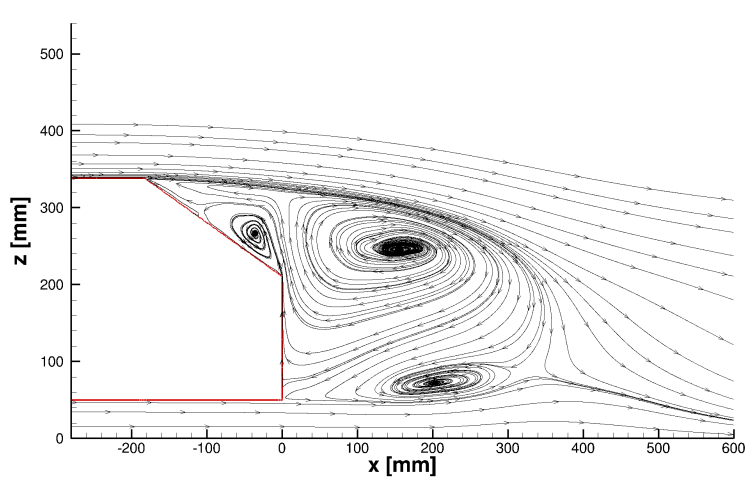

(b) DES (avg)

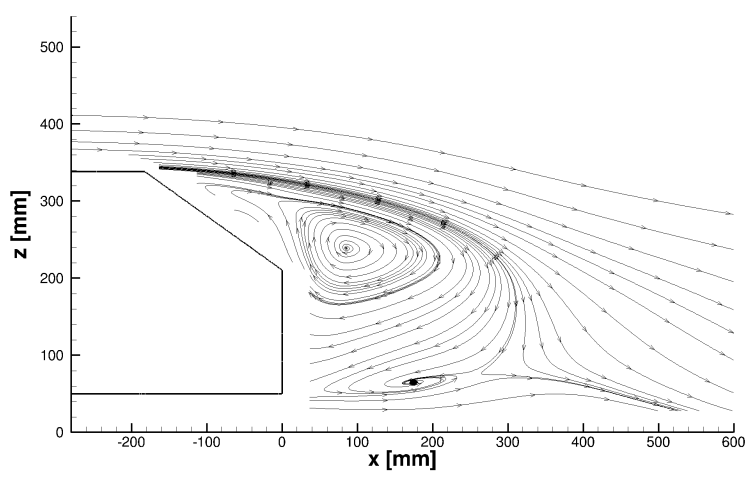

(d) Experiments [5]

Figure 3: $35^{\circ}$ slant angle - Streamlines in the symmetry plane $\mathrm{Y}=0$.

Figure 4 shows a comparison of the streamwise velocity in the symmetry plane for the Ahmed body with the $35^{\circ}$ slant angle. The experimental profiles are those obtained by Lienhart et al. [12]. All turbulence models predict the correct flow, a fully separated flow, in the symmetry pane. The IDDES model gives a better agreement at the shear layer region.

Figure 5 presents the turbulent kinetic energy (TKE) in the symmetry plane. Each model gives a good agreement with the experimental data. Even for a fully separated flow, a RANS model gives a good agreement with the experimental data. This is in agreement with many previous studies, including the ERCOFTAC workshops [13, 11]. At the shear layer, the IDDES model over-predicts TKE while the other models under-predict TKE. In the wake, a better agreement with the experimental data is obtained with the hybrid RANS-LES models.

A comparison of the drag coefficient versus the turbulence model used, with experimental measurements [4], is given in Table 1. The hybrid RANS-LES models overestimated the experimentally measured coefficient of drag. In experiments, it seems that the drag of the feet is not taken into account. For the RANS model, the drag of feet represents $10 \%$ of the drag while for the hybrid RANS-LES approaches, the percentage is $11 \%$. 


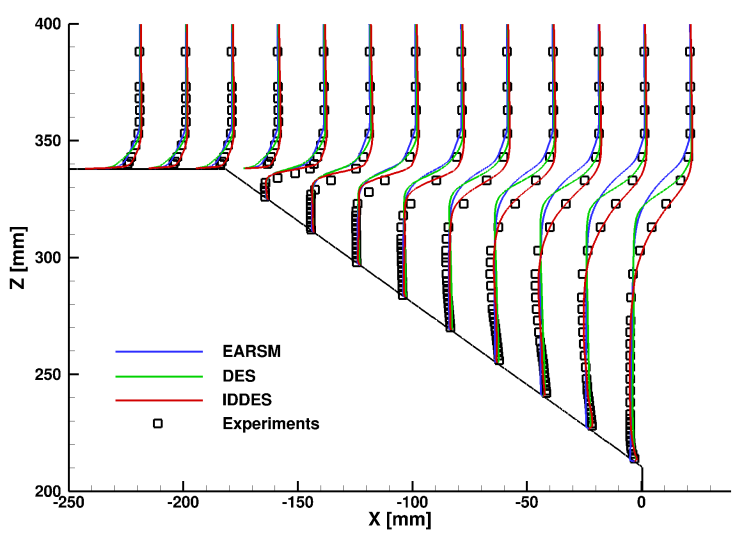

(a) Over the slant

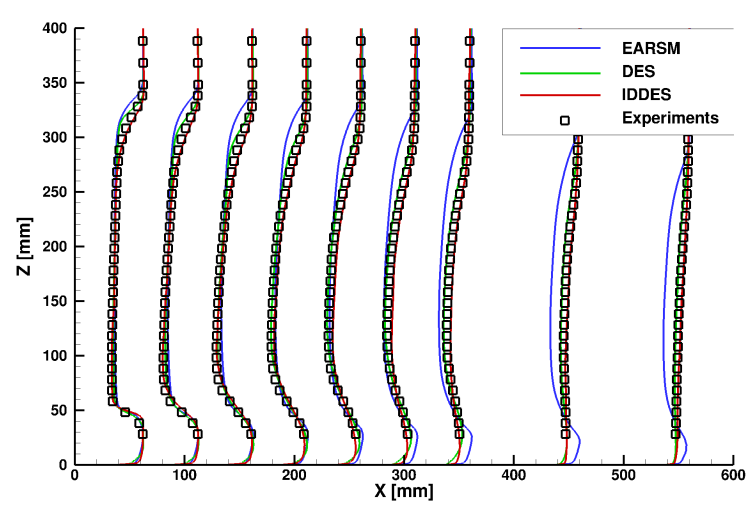

(b) In the wake

Figure 4: $35^{\circ}$ slant angle - Streamwise velocity on the rear slant and in the wake.

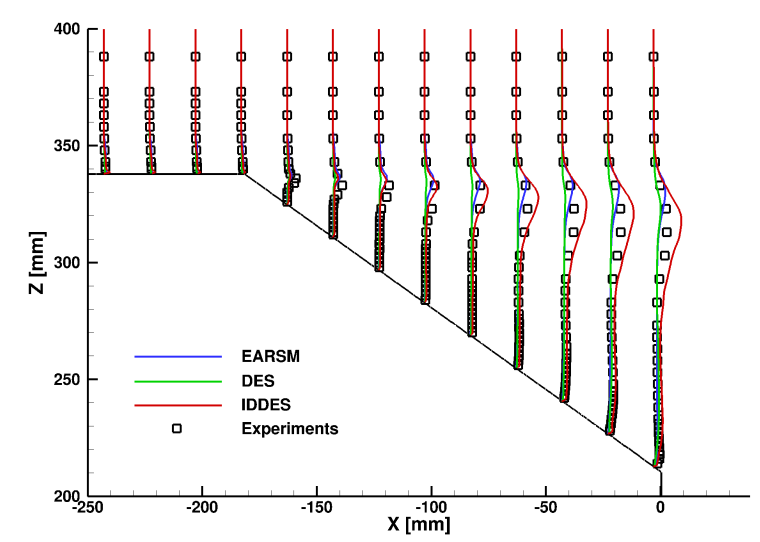

(a) Over the slant

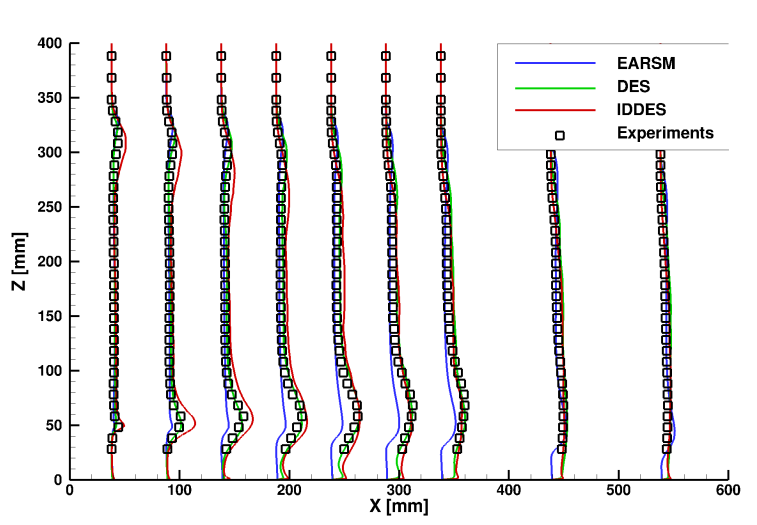

(b) In the wake

Figure 5: $35^{\circ}$ slant angle - Turbulent kinetic energy on the rear slant and in the wake.

\section{$5.225^{\circ}$ slant angle}

Figure 6 presents the vortex structure of the dimensionless Q-criterion for the Ahmed body with the $25^{\circ}$ slant angle. With the RANS model, the C-pillar vortices are not predicted while with the IDDES approach, these vortices are very pronounced. With the hybrid RANS-LES models, a separation bubble is present on the slant.

Figure 7 shows the streamlines in the symmetry plane for all turbulence models compared to the experimental data. With the EARSM model, the results are similar to those of the previous slant angle, i.e. a massive separation. Thus, a RANS model does not see the modification of the geometry. With the hybrid RANS-LES models, the wake is different. The massive separation does not exist, only small separations are present. On the slant, a recirculation bubble is predicted with the IDDES model. The reattachment point is located at $X=168 \mathrm{~mm}$, from the upstream edge of the slant, which is good agreement with the experimental measurement of Thacker [14] for which the value is $X=160 \mathrm{~mm}$. With the DES model, the separation covers the whole slant.

Comparisons of the streamwise velocity profiles with measurements, in the symmetry plane, are presented in Figure 8. As expected, the EARSM turbulence models fails to describe cor- 


\begin{tabular}{cccc}
\hline EARSM & DES & IDDES & Experiments [4] \\
\hline 0.260 & 0.316 & 0.355 & 0.256 \\
\hline
\end{tabular}

Table 1: $35^{\circ}$ slant angle - Drag coefficient.

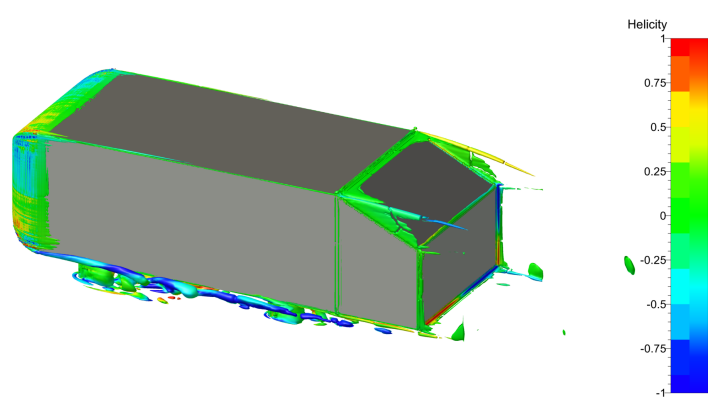

(a) EARSM

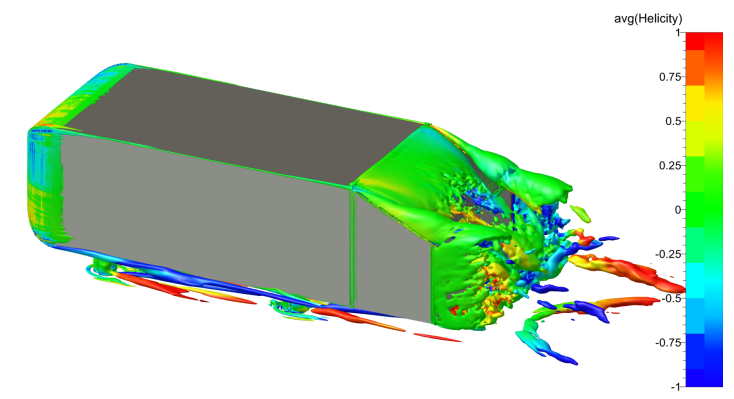

(b) DES (avg flow)

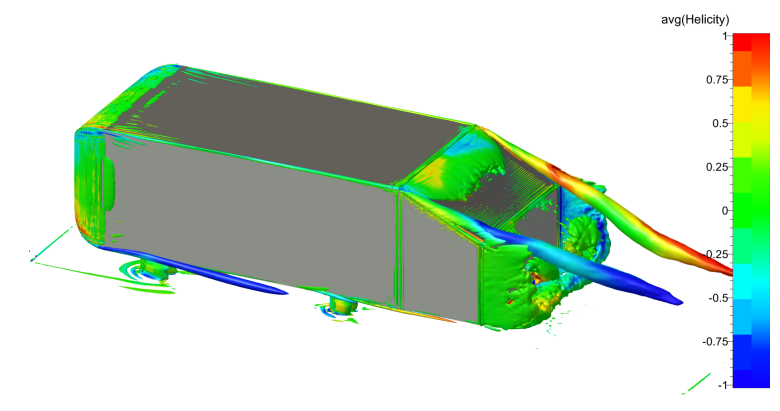

(c) IDDES (avg flow)

Figure 6: $25^{\circ}$ slant angle - Vortex structures around the Ahmed body visualized by iso-surfaces of the nondimensional Q-criterion $(\mathrm{Q}=50)$.

rectly the velocity field and overestimates the size of the recirculation in the wake. The hybrid RANS-LES models provided an improved prediction. In the wake, the results are very similar. On the slant, the IDDES model gives a better agreement due to the recirculation bubble which is correctly predicted.

A comparison of TKE is presented in Figure 9. The TKE obtained with the EARSM turbulence model is underestimated on the slant which means less turbulent mixing and thus a greater recirculation region. With the hybrid RANS-LES models, TKE is larger than the values obtained with the RANS model. In the initial separated region, TKE predicted with the IDDES model is in good agreement with the experimental value.

Table 2 presents a comparison of the drag coefficient. Compared to the previous slant angle, the drag coefficient have increased. The value of the drag is dependent of the turbulence model used. If we compare the drag coefficient measured by Thacker [14], the IDDES model gives the better agreement.

\section{CONCLUSIONS}

In this paper, an investigation of RANS and hybrid RANS-LES models for the Ahmed car body at $25^{\circ}$ and $35^{\circ}$ slant angle cases has been conducted. The RANS model used is the EARSM 


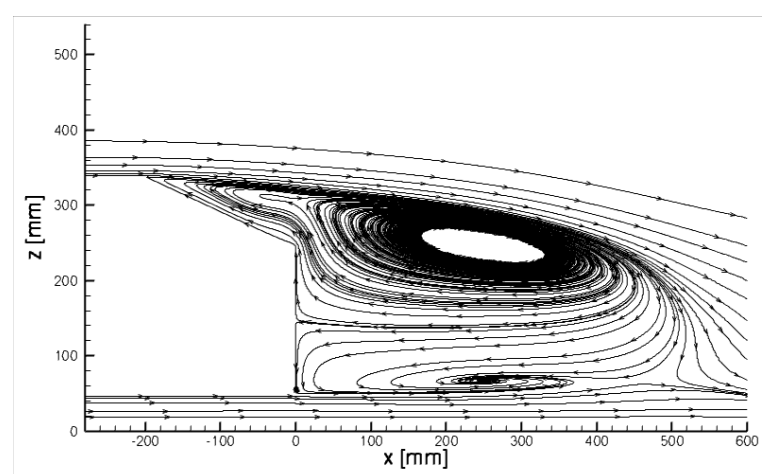

(a) EARSM

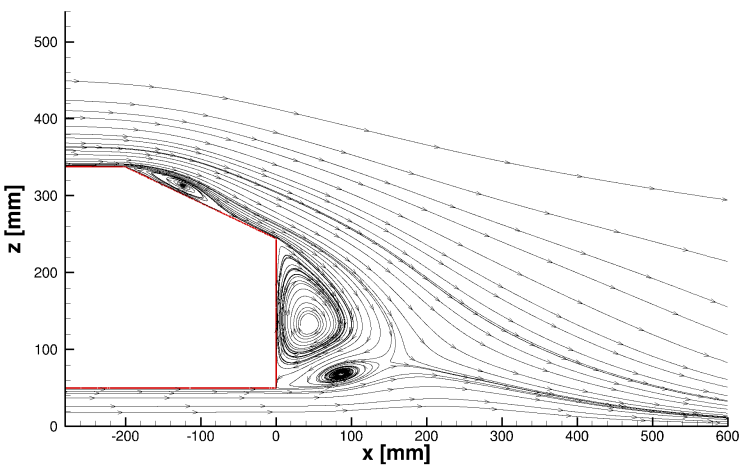

(c) IDDES (avg)

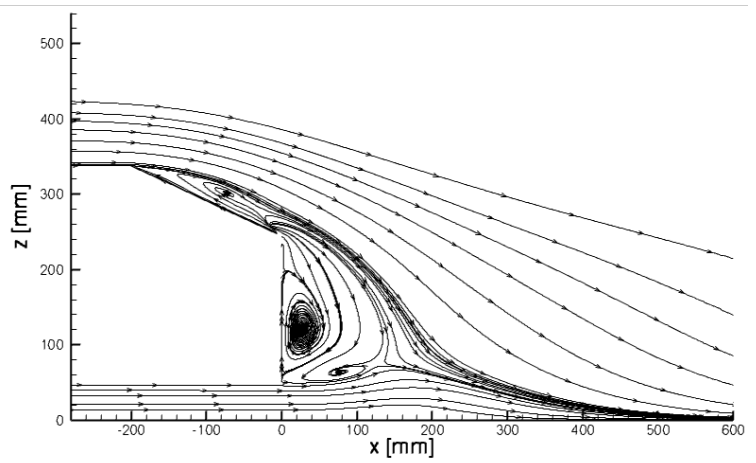

(b) DES (avg)

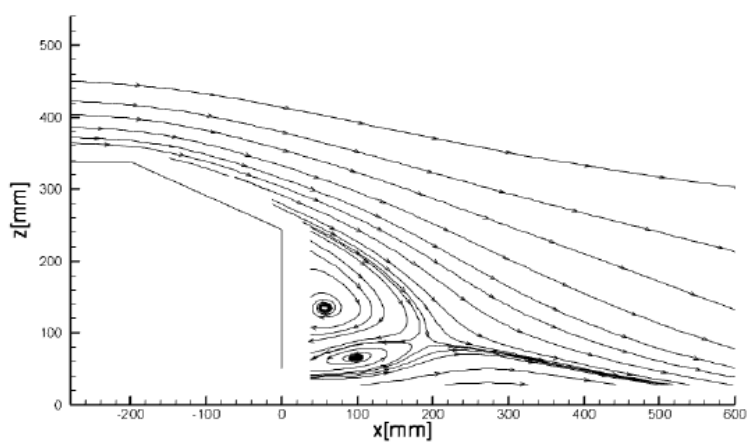

(d) Experiments [5]

Figure $7: 25^{\circ}$ slant angle - Streamlines in the symmetry plane $\mathrm{Y}=0$.

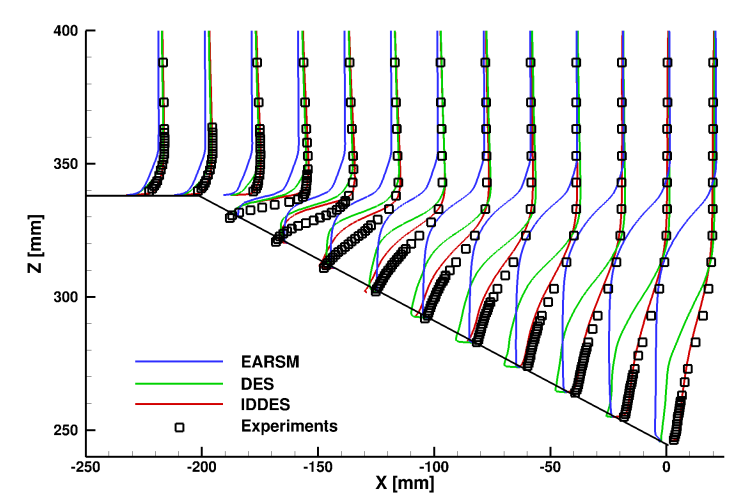

(a) Over the slant

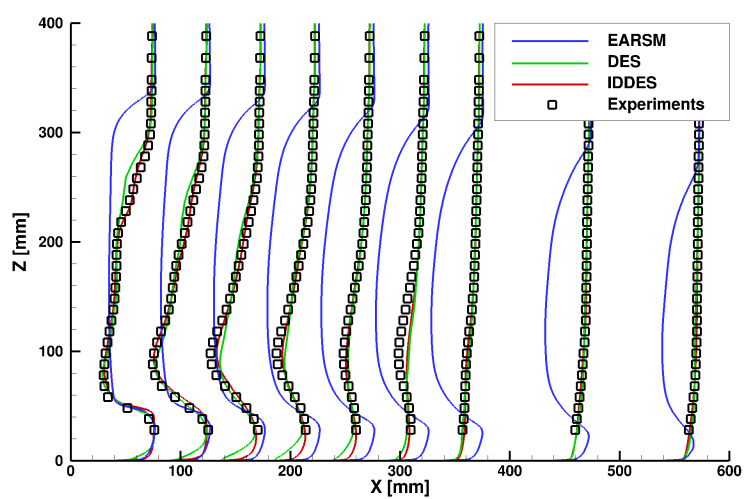

(b) In the wake

Figure 8: $25^{\circ}$ slant angle - Streamwise velocity on the rear slant and in the wake.

turbulence model and the hybrid RANS-LES models are the DES model and the IDDES model. These both models are based on the k- $\omega$ SST model. It has been shown that the use of a hybrid RANS-LES model, in particular the IDDES model, offers an advantage over RANS model in terms of the force coefficients and general flow field, even for the $25^{\circ}$ test case where the reattachment of the flow is correctly predicted. Only, the IDDES model predicts the flow correctly for both slant angles. With the RANS model, a massive separation is present for both 


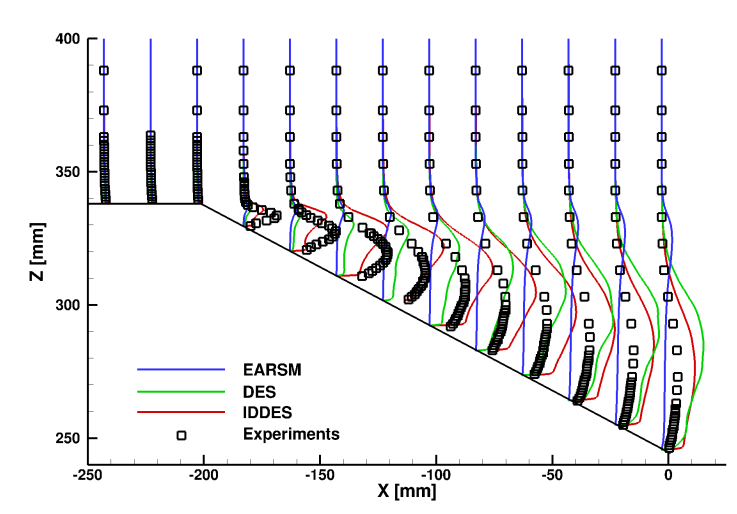

(a) Over the slant

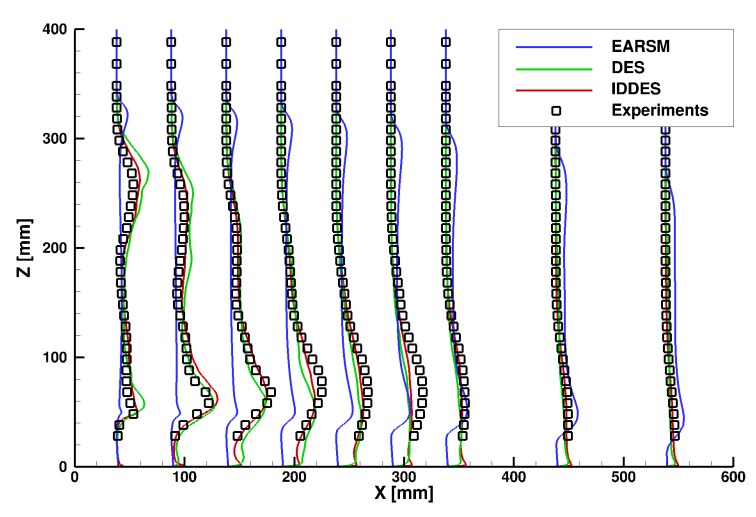

(b) In the wake

Figure 9: $25^{\circ}$ slant angle - Turbulent kinetic energy on the rear slant and in the wake.

\begin{tabular}{ccccc}
\hline EARSM & DES & IDDES & Experiments [4] & Experiments [14] \\
\hline 0.280 & 0.437 & 0.382 & 0.285 & 0.384 \\
\hline
\end{tabular}

Table 2: $25^{\circ}$ slant angle - Drag coefficient.

slant angles.

\section{ACKNOWLEDGMENT}

This work was granted access to the HPC resources of CINES/IDRIS under the allocation 2015-2a0129 made by GENCI.

\section{REFERENCES}

[1] W.H. Hucho, Aerodynamics of road vehicles. SAE International, 1998.

[2] P. R. Spalart, W. Jou, M. Strelets, S. Allmaras, Comments on the feasibility of LES for wings and on a hybrid RANS/LES approach, 1st AFOSR International Conference on DNS/LES (C. . Z. Liu, ed.), Advances in DNS/LES, Greyden Press, 1997.

[3] N. Ashton, A. West, S. Lardeau, A. Revell, Assessment of RANS and DES methods for realistic automotive models, Computers and Fluids, 128, 1-15, 2016.

[4] S.R. Ahmed, G. Ramm, G. Faltin, Some salient features of the time-averaged ground vehicle wake. SAE World Congress, Paper 840300, 1984.

[5] H. Lienhart, S.Becker, Flow and turbulence in the wake of a simplified car model. SAE World Congress, Paper 2003-01-0656, 2003.

[6] P. Queutey, M. Visonneau, An interface capturing method for free-surface hydrodynamic flows, Computers and Fluids, 36, 1481-1510, 2007.

[7] R. Duvigneau, M. Visonneau, G.B. Deng, On the role played by turbulence closures in hull ship optimization at model and full scale, Journal of Marine Science and Technology, 8, 11-25, 2003. 
[8] G.D. Deng, M. Visonneau, Comparison of explicit algebraic stress models and secondorder turbulence closures for steady flow around ships, 7th Symposium on Numerical Ship Hydrodynamics, Nantes, France, July 1999.

[9] E. Guilmineau, G.B. Deng, J. Wackers, Numerical simulation with a DES approach for automotive flows, Journal of Fluids and Structures, 27, 807-816, 2011.

[10] M.S. Gritskevich, A.V. Garbaruk, J.Schütze, F. R. Menter, Development of DDES and IDDES formulations for the k- $\omega$ shear stress transport model, Flow, Turbulence and Combustion, 88, 431-449, 2012.

[11] R. Manceau, J.Bonnet, eds., 10th joint ERCOFTAC/IAHR/QNET-CFD Workshop on Refined Turbulence Modelling, Poitiers, France 2002.

[12] H. Lienhart, C. Stoots, S. Becker, Flow and turbulence structures in the wake of a simplified car model Ahmed model), DGLR Fach Symposium der AG STAB, Stuggart University, November 2000.

[13] S. Jakirlić, R. Jester-Zrker, C. Tropea, eds., 9th joint ERCOFTAC/IAHR/QNET-CFD Workshop on Refined Turbulence Modelling, Darmstadt, Germany 2001.

[14] A. Thacker, Contribution expérimentale à l'analyse stationnaire et instationnaire de l'écoulement à l'arrière d'un corps de faible allongement. $\mathrm{PhD}$ thesis, Université d'Orléans, 2010. 